\title{
Analysis on Convergence of Innovation Resource Attraction and Its Affecting Factors in Chinese Provinces: Based on the Perspective of New Input Allocation
}

\author{
Feng Feng ${ }^{1}$, Zhouqing $\mathrm{Wei}^{1}$ \& Leiyong Zhang ${ }^{1}$ \\ ${ }^{1}$ School of Management, University of Science and Technology of China, Hefei, China \\ Correspondence: Zhouqing Wei, School of Management, University of Science and Technology of China, \\ No.316, 365 building, East Campus, USTC, Hefei, China. E-mail: wzq1988@mail.ustc.edu.cn
}

Received: May 20, 2012 Accepted: June 19, 2012 Online Published: September 20, 2012

doi:10.5539/ass.v8n12p88 URL: http://dx.doi.org/10.5539/ass.v8n12p88

This paper is sponsored by Natural Science Foundation of China (Grant NO.71073151)

\begin{abstract}
Based on the panel data of China's provinces from 2002 to 2009, the paper allocates new input resources among provinces reasonably using the DEA method and conducts an empirical analysis of innovation resources attraction. As indicated by the research, the innovation resource attraction in China shows the typical characteristic of zonal distribution, the east region is higher than the middle and west; the condition convergence of all provinces is identified, but the absolute convergence is not remarkable; the educational level and industry structure have positive influences, the openness and the level of government support have opposite impacts on different regions.
\end{abstract}

Keywords: new input, resource attraction, convergence, Tobit model, DEA(data envelopment analysis)

\section{Introduction}

In the context of increasingly globalization of economy, science and technology, the innovation ability of regional scinence and technology innovation system becomes the crucial factor in gaining competitive advantage. Nowadays technology progress and innovation has become the engine and trigger to pull the new round of economic growth and all regions are striving to develop S\&T innovation system. Peter F Drucker believes that technology innovation is a progress of producing new knowledge with existing knowledge and this creative progress depends on the innovation resource input related to accumulation of knowledge and knowledge innovation. The ability of attracting S\&T innovation resource is an important symbol of the development level of S\&T innovation system and the economic development potential. With the deep implementation of the strategy of revitalizing China through science and education, China has been increasing S\&T innovation resource input. To seize the opportunity, a competition for new innovation resource has been more and more obvisous and fierce. the flow of new innovation resource is becoming the focus of attention. Therefore, researches on new innovation resource attraction level and evolution trend of different areas have very important practical significance.

\section{Studies Review}

At present, there are few researchers focusing on S\&T innovation resource attraction of different areas, while most of them in China are interested in the evaluation of efficiency of innovation resource allocation. For example, Liu(2008) used Malmquist Index Approach to calculate the technical efficiency, technical progress and Malmquist Indexes in China's 30 provinces from 1988 to 2005, which finding that the promotion of resource allocation efficiency growth in three regions has different reasons. Furthermore, REM model was used to testify empirically the relations between the allocation efficiency and the influential factors. Wei and $\mathrm{Wu}(2005)$ constructed a S\&T resource allocation efficiency model according to Cobb-Douglas function, and employed cluster analysis method to analyze the resource allocation efficiency in various regions. The study indicated that the S\&T resource allocation efficiency shows a descending order by East, Middle, West and the level of resource allocation efficiency is closely related to resource inputs and economic development. Niu et al. (2004) evaluated the S\&T resource allocation in each province with GIS and SPSS methods and concluded that there is great 
regional difference in China and it's absolutely related to regional economical disparity. Li et al. (2003) analyzed the allocation efficiency of S\&T resource of China's 30 provinces by means of statistics methods including data reduction and classification. The study revealed that unbalanced regional economy development is the cause of low allocation efficiency and high input for scientific research also lead to low allocation efficiency. The level of resource allocation efficiency reflects the usage of innovation resource of various regions. However, because of the scales of innovation resource in different areas existing large disparity, evaluation of allocation efficiency can not achieve the percent of new innovation resource of different areas.

In view of this, this paper begin with the estimation of new resource attraction of different areas which is represented by allocation ratio from 2002 to 2009 using data envelopment analysis from the perspective of new input allocation, and then the convergence analysis of interprovincial attraction of innovation resource, finally the regression analysis of factors affecting the attraction of the regional innovation resource and some meaningful suggestions.

\section{Measurement of Attraction of Innovation Resource}

\subsection{Absolute Value Model of CCR Considering New Inputs}

Data envelopment analysis(DEA) created by Charnes and Cooper in 1978 is a new cross-cutting areas of mathematics, operations research, mathematical economics and management science(Charnes A, 1978,429-444). DEA has proven to be effective approach which is widely used in various aspects of economics and management domains. DEA method was firstly introduced to the issue of resource allocation by Golany et al. in 1993, they established the additive DEA model in which the DMU's efficiency values are weights to determine the inputs of each DMU (Golany B, 1993, 2-10).

As new innovation resource will increase the inputs of areas, we consider it as a new kind of input elements of the DMU (Wu Huaqing, 2009, 104-107). Yongjun Li(2008) has proved that there is some allocation schemes about new inputs which could optimize DMU in terms of its individual and overall efficiency. CCR model could generate a set of allocation scheme ensuring the DMU both individual and overall efficiency. Resource attraction can be represented by allocation ratio. The set is as follows:

$$
\Omega=\left\{\left(E_{1}, \cdots, E_{n}\right) / E_{j}=\sum_{r=1}^{s} u_{r} y_{r j}-\sum_{i=1}^{m} v_{i} x_{i j}, \sum_{j=1}^{n} E_{j}=E, E_{j} \geq 0, \forall j\right\}
$$

In this allocation scheme, $A_{d}=1$ and $A_{\text {all }}=1, A_{d}$ is the efficiency of each DMU, $A_{\text {all }}$ is the overall efficiency of DMUs. The DMU is denoted by $\mathrm{DMU}_{\mathrm{j}}(\mathrm{j}=1,2, \ldots, \mathrm{n})$, each DMU uses $m$ inputs $\mathrm{X}_{\mathrm{ij}}(\mathrm{i}=1,2, \ldots, \mathrm{m})$ to produce $s$ outputs $\mathrm{Y}_{\mathrm{rj}}(\mathrm{r}=1,2, \ldots, \mathrm{s})$. E is the amount of new innovation resource, and $u$ and $v$ respectively represent the weight of input and output.

Because the set of allocation scheme described above might lead to imbalanced resource allocation of different areas, this article introduces the absolute value model which can maximize the average allocation of new inputs. The objective function is to minimize the sum of the gap of resource allocation of each DMU in the system.

$$
\begin{aligned}
& {\underset{u}{u}, i_{v}}_{j} \sum_{j=1}^{n}\left|E_{j}-\bar{E}^{-}\right| \\
& \text {s.t. } E_{j}=\sum_{r=1}^{S} u_{r} y_{r j}-\sum_{i=1}^{m} v_{i} x_{i j}, \forall j \\
& \sum_{j=1}^{n} E_{j}=E \\
& u_{r}, v_{i}, E_{j} \geq 0, \forall r, i, j
\end{aligned}
$$

Note that $\bar{E}=E / n$, it is easy to know that the absolute value model is nonlinear, and in order to facilitate the calculation, let $a_{j}=\left[E_{j}-\bar{E} \mid+E_{j}-\bar{E}\right] / 2, b_{j}=\left[\left|E_{j}-\bar{E}\right|-E_{j}+\bar{E}\right] / 2$, then get the linear equivalent model:

$$
\begin{aligned}
& M i_{, v} \sum_{j=1}^{n}\left(a_{j}+b_{j}\right) \\
& \text { s.t. } \sum_{r=1}^{S} u_{r} y_{r j}-\sum_{i=1}^{m} v_{i} x_{i j}-a_{j}+b_{j}=\bar{E}, \forall j \\
& \quad \sum_{j=1}^{n}\left(a_{j}-b_{j}\right)=0 \\
& a_{j}-b_{j}+E \geq 0 \\
& u_{r}, v_{i}, a_{i}, b_{j} \geq 0, \forall r, i, j
\end{aligned}
$$

The optimal solutions of the model are $u_{r}^{*}, v_{i}^{*}, a_{i}^{*}, b_{j}^{*}$, and the optimal allocation scheme is $E_{j}^{*}=a_{j}^{*}-b_{j}^{*}+\bar{E}, \forall j$. 


\subsection{Construction of Index System and Data Selection}

Regional input-output condition including both inputs and outs is the basis of new innovation resource allocation, we regard the new innovation resource as a new kind of input element. Following the principles of scientific, representativeness, practicality and hierarchy, this paper constructs an input-output index system of S\&T innovation based on the existing research literature (Yu Yongze, 2009, 62-74; Zhou Linquan, 2010, 50-53; Feng Ying, 2010, 107-112).

S\&T innovation inputs include innovation personnel, innovation funding and the new innovation resource. Considering the difference of statistical standards of year-end report in different years, we select full-time equivalent of $R \& D$ personnel (person) and intramural expenditure on $R \& D$ (ten thousand yuan) respectively as innovation personnel input and innovation funding input.

The capability of S\&T innovation output can be evaluated from the output of S\&T and innovative products. S\&T output index include patents granted (unit) and number of paper published/accepted by major foreign referencing systems(piece), and innovative products output index includes gross value of new products(ten thousand yuan) and revenue of new products(ten thousand yuan).

Due to the lag between input and output, we use $\mathrm{T}$ and $\mathrm{T}+1$ year indexes represent inputs and outputs (Yang Hongtao, 2007, 102-105). This paper selected the panel data of China's 29 provinces (autonomous regions) and municipalities (Xinjiang and Tibet are not included) from 2002 to 2009, and these data are derived from $<<$ China statistical yearbook on science and technology $>>,<<$ China statistical yearbook on high-tech industry $>>$ and related data from S\&T statistical website of ministry of S\&T of the people's republic of China.

\subsection{Measurement of Regional Innovation Resource Attraction}

Using the linear equivalent model listed above, we measured the attraction level of China's 29 provinces from 2002 to 2009 and represented it by the allocation ratio of new innovation resource. The results are shown in table 1.

Table 1. Innovation resource attraction level of China's 29 provinces from 2002 to 2009

\begin{tabular}{|c|c|c|c|c|c|c|c|c|c|}
\hline & 2002 & 2003 & 2004 & 2005 & 2006 & 2007 & 2008 & 2009 & mean \\
\hline Beijing & 0.1804 & 0.1830 & 0.2172 & 0.2253 & 0.2075 & 0.2039 & 0.1951 & 0.1864 & 0.1998 \\
\hline Tianjin & 0.0324 & 0.0345 & 0.0345 & 0.0365 & 0.0356 & 0.0307 & 0.0298 & 0.0290 & 0.0329 \\
\hline Hebei & 0.0199 & 0.0189 & 0.0120 & 0.0145 & 0.0143 & 0.0153 & 0.0192 & 0.0168 & 0.0164 \\
\hline Shanxi & 0.0096 & 0.0116 & 0.0093 & 0.0130 & 0.0091 & 0.0082 & 0.0107 & 0.0090 & 0.0101 \\
\hline Neimenggu & 0.0042 & 0.0038 & 0.0024 & 0.0023 & 0.0024 & 0.0027 & 0.0029 & 0.0030 & 0.0030 \\
\hline Liaoning & 0.0412 & 0.0420 & 0.0424 & 0.0444 & 0.0490 & 0.0520 & 0.0459 & 0.0467 & 0.0454 \\
\hline Jilin & 0.0223 & 0.0239 & 0.0269 & 0.0302 & 0.0294 & 0.0272 & 0.0264 & 0.0263 & 0.0266 \\
\hline Heilongjiang & 0.0234 & 0.0253 & 0.0335 & 0.0343 & 0.0374 & 0.0389 & 0.0380 & 0.0381 & 0.0336 \\
\hline Shanghai & 0.0995 & 0.1053 & 0.1145 & 0.1161 & 0.1091 & 0.0993 & 0.0980 & 0.0968 & 0.1048 \\
\hline Jiangsu & 0.0758 & 0.0732 & 0.0675 & 0.0712 & 0.0754 & 0.0783 & 0.0828 & 0.0891 & 0.0767 \\
\hline Zhejiang & 0.0631 & 0.0692 & 0.0684 & 0.0584 & 0.0596 & 0.0554 & 0.0521 & 0.0526 & 0.0599 \\
\hline Anhui & 0.0271 & 0.0201 & 0.0316 & 0.0312 & 0.0317 & 0.0296 & 0.0269 & 0.0260 & 0.0280 \\
\hline Fujian & 0.0345 & 0.0300 & 0.0192 & 0.0147 & 0.0158 & 0.0166 & 0.0170 & 0.0178 & 0.0207 \\
\hline Jiangxi & 0.0066 & 0.0055 & 0.0032 & 0.0044 & 0.0061 & 0.0070 & 0.0080 & 0.0094 & 0.0063 \\
\hline Shandong & 0.0493 & 0.0470 & 0.0345 & 0.0348 & 0.0379 & 0.0416 & 0.0449 & 0.0420 & 0.0415 \\
\hline Henan & 0.0153 & 0.0137 & 0.0113 & 0.0100 & 0.0122 & 0.0148 & 0.0187 & 0.0194 & 0.0144 \\
\hline Hubei & 0.0342 & 0.0406 & 0.0521 & 0.0603 & 0.0565 & 0.0602 & 0.0603 & 0.0595 & 0.0530 \\
\hline Hunan & 0.0237 & 0.0257 & 0.0305 & 0.0300 & 0.0363 & 0.0377 & 0.0374 & 0.0385 & 0.0325 \\
\hline Guangdong & 0.1194 & 0.1089 & 0.0641 & 0.0345 & 0.0404 & 0.0423 & 0.0417 & 0.0443 & 0.0620 \\
\hline Guangxi & 0.0062 & 0.0055 & 0.0049 & 0.0043 & 0.0049 & 0.0055 & 0.0062 & 0.0070 & 0.0056 \\
\hline Hainan & 0.0020 & 0.0020 & 0.0014 & 0.0015 & 0.0016 & 0.0017 & 0.0016 & 0.0018 & 0.0017 \\
\hline Chongqing & 0.0124 & 0.0159 & 0.0139 & 0.0139 & 0.0134 & 0.0136 & 0.0149 & 0.0180 & 0.0145 \\
\hline
\end{tabular}




$\begin{array}{llllllllll}\text { Sichuan } & 0.0326 & 0.0312 & 0.0345 & 0.0338 & 0.0365 & 0.0390 & 0.0397 & 0.0395 & 0.0359 \\ \text { Guizhou } & 0.0045 & 0.0043 & 0.0032 & 0.0025 & 0.0027 & 0.0031 & 0.0033 & 0.0034 & 0.0034 \\ \text { Yunnan } & 0.0096 & 0.0084 & 0.0071 & 0.0060 & 0.0066 & 0.0066 & 0.0069 & 0.0082 & 0.0074 \\ \text { Shanxi } & 0.0345 & 0.0345 & 0.0402 & 0.0506 & 0.0504 & 0.0507 & 0.0526 & 0.0528 & 0.0458 \\ \text { Gansu } & 0.0122 & 0.0121 & 0.0171 & 0.0182 & 0.0153 & 0.0153 & 0.0159 & 0.0156 & 0.0152 \\ \text { Qinghai } & 0.0017 & 0.0020 & 0.0014 & 0.0016 & 0.0016 & 0.0016 & 0.0016 & 0.0016 & 0.0016 \\ \text { Ningxia } & 0.0022 & 0.0019 & 0.0012 & 0.0013 & 0.0015 & 0.0014 & 0.0015 & 0.0015 & 0.0016 \\ \text { Mean of east } & 0.0652 & 0.0649 & 0.0614 & 0.0593 & 0.0587 & 0.0579 & 0.0571 & 0.0567 & 0.0602 \\ \text { Mean of middle } & 0.0203 & 0.0208 & 0.0248 & 0.0267 & 0.0273 & 0.0279 & 0.0283 & 0.0283 & 0.0255 \\ \text { Mean of west } & 0.0120 & 0.0120 & 0.0126 & 0.0135 & 0.0135 & 0.0139 & 0.0146 & 0.0151 & 0.0134\end{array}$

As shown in the table, the new inputs attraction level in eastern coastal areas far exceeds the central and western areas, and the attraction level in the central is between the eastern and western. In recent years, the resource attraction level of middle and western regions has improved continuously, but the magnitude is not high and it is impossible to reach the same level as in eastern regions in a short period. Beijing, Shanghai, Jiangsu and Zhejiang have maintained at a high attraction level for years, and Beijing has been at the top of the 29 areas. Guangdong ranked secondly, behind Beijing, in 2002, but declined significantly after that, ranking 7th of 29 provinces by 2009. Areas which have lower attraction level, such as Qinghai, Ningxia, Hainan, not only failed to improve their attraction level, but there was a slight downward trend.

\section{Convergence Analysis of the Regional Innovation Resource Attraction}

In the past decade, the convergence economy growth theory has gained more and more research attention. In order to further investigate the evolution trend of resource attraction in various regions, we carried out a convergence analysis on attraction level of three regions in China.

\subsection{Absolute Convergence Analysis}

We calculated the coefficient of variation of resource attraction in China's three regions from 2002 to 2009 using the attraction level proposed above. The results are shown in Figure 1.

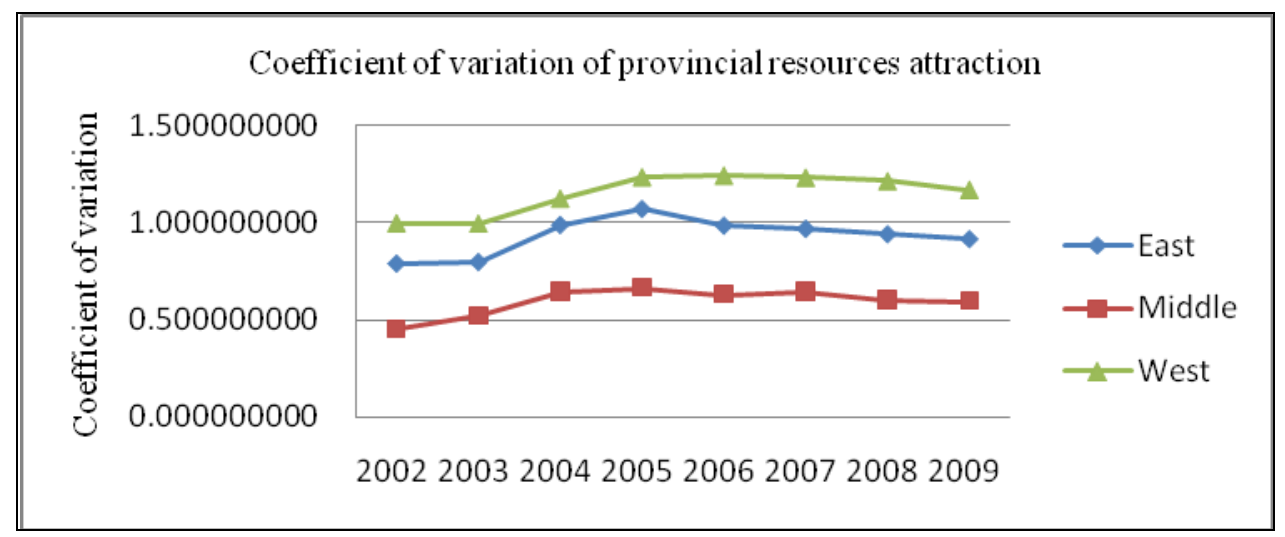

Figure 1.

As shown above, none of these three regions demonstrates a significant convergence, the coefficient of variation is diverge from 2002 to 2005, and shows a steady downward trend after that. For different regions, the results varies. The coefficient of variation in the central region has been smallest and relatively stable, indicating that the gap of resource attraction is small and the fluctuation is not obvious, and it slows down after reaching its peak in 2005. The coefficient of variation of west is the highest among the three regions, representing that the attraction level in western region is significantly uneven. The coefficient of variation of east is between the western and central, and its volatility is the highest. The internal gap increased from 2002 to 2005, and the convergence trend is relatively obvious compared with central and western region since then.

In the following step, we will use a single equation to test the absolute $b$ convergence of resource attraction level of China's three major regions, the regression equation is as follows:

$$
\left(\ln E_{t}-\ln E_{t-1}\right) / T=\alpha+\beta \ln E_{t-1}+\varepsilon
$$


$\ln E_{t}$ and $\ln E_{t-1}$ respectively represent the average of the logarithm of resource attraction from 2008 to 2009 and from 2002 to $2003, \varepsilon$ is the random disturbance tem. The two periods are separated by T=6 years, we consider the result of logarithmic difference divided by 6 as the average annual growth rate. Regression results are shown in table 2.

Table 2. The OLS regression results of absolute $b$ convergence

\begin{tabular}{cccccc}
\hline region & explanatory variable & coefficient value & T test value & $\mathrm{R}^{2}$ & $\mathrm{~F}$ value \\
\hline east & Intercept & -0.04138 & -0.81 & & \\
& coefficient $\beta$ & -0.00342 & -0.22 & 0.0055 & 0.05 \\
central & Intercept & 0.11626 & 1.33 & & \\
& coefficient $\beta$ & 0.01781 & 0.83 & 0.1024 & 0.68 \\
west & Intercept & 0.17744 & 4.06 & & \\
& coefficient $\beta$ & $0.03658^{*}$ & 4.16 & 0.6840 & 17.32 \\
\hline
\end{tabular}

Note: Xinjiang and Xizang are not included.

*means significant at 5\% level.

We can find that the western region is divergent at the $5 \%$ significance level, indicating that the gap of resource attraction among western areas is widening. Eastern region has the symbol of convergence, the resource attraction levels of various areas have a tendency to a common level, but extremely non-significant. The central region has the symbol of divergence, the internal gap is expanding, but not to a great level.

\subsection{Conditional Convergence Test}

Random effects assume non-observed effect and explanatory variable are uncorrelated, while fixed effects do not have this assumption. This assumption is deemed inappropriate, as pointed out by Islam (1995). Miller and Upadhway (2002) used the fixed effects model directly. From the perspective of priori theory, we think adopting the fixed effects directly is reasonable. We use equation (2) to conduct the analysis of conditional convergence.

$$
\ln E_{i, t}-\ln E_{i, t-1}=\alpha+\beta \ln E_{i, t-1}+\varepsilon
$$

We divided the sample into $\mathrm{t}=4$ periods, so each period is 2 years. Specifically, we calculated the each period's average of logarithmic of resource attraction, denoted by $\ln E_{i, t}(\mathrm{i}=1,2, \ldots, 29)$. The regression results of conditional convergence are shown in table 3 .

Table 3. Results of conditional convergence test

\begin{tabular}{ccccc}
\hline region & coefficient & Intercept & AD.R & T value \\
\hline east & $-0.982393^{*}$ & -3.290183 & 0.810872 & -8.987363 \\
central & $-1.209061^{*}$ & -4.650599 & 0.358676 & -4.509277 \\
west & $-1.117112^{*}$ & -5.547956 & 0.907754 & -12.84835
\end{tabular}

Note: Xinjiang and Xizang are not included.

*means significant at $1 \%$ level.

The regression coefficients of conditional convergence are all less than zero in China's three major regions and their conditional convergence are at the $1 \%$ significant level. This suggests that the resource attraction of each region approaches towards their respective steady state level, and the steady state level depends on the characteristics of different regions.

\section{Study on the Factors Affecting Regional Resource Attraction}

\subsection{Model Selection and Data Description}

Tobit model is an econometric model proposed by Nobel laureate in economics Tobin in 1958. An important feature of the model is that explanatory variable is an actual observation while the dependent variables are restricted, which means the model is used when the explanatory variable is cutting value or fragment value. Resource attraction level is represented by the allocation proportion of new inputs, which is between 0 and 1 . So Tobit model can be used to research the factors affecting the resource attraction.

This paper focuses on the effects of level of industrialization, openness, level of education and level of government support on resource attraction. The level of industrialization is denoted by the ratio of High-tech 
industrial output value to gross industrial output value of industrial enterprises above designated size, and the openness refers to the proportion of import value of commodities by destination and export value of commodities by origin to GDP. The level of education is indicated by the number of high education students per 100000 population. The level of government support is the proportion of S\&T financial allocation to S\&T expenditure. The Tobit model is as follows:

$$
\begin{aligned}
& E C_{i t}^{*}=C+\beta_{1} I L_{i t}+\beta_{2} O L_{i t}+\beta_{3} H L_{i t}+\beta_{4} G L_{i t}+\varepsilon_{i t} \\
& E C_{i t}=E C_{i t}^{*}, \quad E C_{i t}^{*}>0 \\
& E C_{i t}=0, \quad E C_{i t}^{*} \leq 0
\end{aligned}
$$

Resource attraction is denoted by $E C_{i t}(\mathrm{i}=1,2, \ldots, 29 ; \mathrm{t}=1,2, \ldots, 8) . \mathrm{IL}, \mathrm{OL}, \mathrm{HL}, \mathrm{GL}$ respectively represent the level of industrialization, openness, education and government support.

\subsection{Results and Analysis}

This paper calculated the Tobit regression coefficient of the four factors in China's three major regions using stata10.0 based on the panel data from 2002 to 2009 . The results are shown in table 4 .

Table 4. Tobit regression results of factors affecting resource attraction

\begin{tabular}{cccccc}
\hline region & Explanatory variable & IL & OL & EL & GL \\
\hline east & coefficient $\beta$ & $0.3624477^{* * *}$ & 0.0359315 & $0.3885778^{*}$ & 0.2081082 \\
& t value & 1.93 & 0.22 & 2.64 & 1.43 \\
cetral & coefficient $\beta$ & 0.0389557 & -0.0396617 & $0.3829585^{*}$ & $0.2209643 * *$ \\
& t value & 0.40 & -0.41 & 3.62 & 2.34 \\
west & coeffiecient $\beta$ & $1.255931^{*}$ & $0.2667232 * * *$ & $0.7004605 *$ & $-0.6229083 *$ \\
& t value & 3.77 & 1.73 & 3.03 & -1.65 \\
\hline
\end{tabular}

Note: Xinjiang and Xizang are not included.

*means significant at 1\% level, **means significant at 5\% level, ***means significant at 10\% level.

As shown in the table, industrial structure has positive effect on resource attraction in any of the three regions, indicating that higher the proportion of high-tech industries accounting for the industrial enterprises above designated size, the stronger the resource attraction. However, its impact on the central region is not statistically significant. The openness posts positive influence on resource attraction in western regions, which may be related to the backward area and the introduction of advanced technologies and progresses in western regions. In addition, the impact of openness on eastern and central regions are not statistically significant, and further research is recommended. Overall the level of education positively influences resource attraction. The results show that education is the only factor whose regression result is significantly positive in China's three regions. Government support level also has positive effect in eastern and central regions, but significantly negative in west. This might be incurred by the poor dominant position of enterprises in S\&T innovation, therefore, increasing proportion of S\&T financial allocation weakens the resource attraction.

\section{Conclusions and Suggestions}

Throughout the analysis on convergence of innovation resource attraction and its affecting factors, we have these following findings: 1) The resource attraction levels in China's three major regions show a typical zonal distribution. The attraction level in eastern coastal regions is much higher than the central and western regions, and the western region is worst. In recent years the resource attraction levels in central and western regions have improved, but there is still a large gap compared with eastern areas. 2)During the period there was no apparent a convergence in the three regions, and the OLS regression coefficient in western region is significantly divergent. All of the three regions are conditional convergent at the $1 \%$ significance level, that is to say, various areas of the region are approaching towards their respective steady state level. 3) The level of education and industrial structure have positive effects on resource attraction in China, and the effect of openness is positive in eastern and western regions, while negative in central region, and government support has positive effect in western region, while negative in eastern and central regions.

According to these findings, we suggest that:

1) Make a rational allocation of new inputs based on resource attraction level represented by allocation 
proportion.

2) Through establishing the dominant position of enterprises in S\&T innovation, we can maximize the guiding role of government financial support and improve the efficiency of innovation.

3) Strive to develop education and high-tech industry, cultivate a number of innovation talents of quality and culture, and optimize the industrial structure continuously.

4) Focus on the innovation of S\&T policy, and expand the openness of backward areas, and introduce some advance technologies and progresses.

\section{References}

Charnes, A., Cooper, W. W., \& Rhodes, E. (1978). Measuring the efficiency of decision making units. European Journal of Operations Research, 2, 429-444. http://dx.doi.org/10.1016/0377-2217(78)90138-8

Feng, Ying, \& Teng, Jiajia. (2010). Evaluation on technology innovation efficiency of high-tech industry in jiansu province. Science of Science and Management of S. \&T, 8, 107-112.

Golany, B., Phillips, F. Y., \& Rousseeau J. J. (1993). Models for improved effectiveness based on DEA efficiency results. IIE Transactions, 25, 2-10. http://dx.doi.org/10.1080/07408179308964322

Islam, N. (1995). Rowth empirics: a panel data approach. Quarterly Journal of Economics, 110, 1127 -1170. http://dx.doi.org/10.2307/2946651

Li, Dongmei, Li, Shizhu, \& Tang, Wuxiang. (2003). Evaluation of allocation efficiency of China's regional science \& technology resources. Journal of Beijing Institute of Achinery, 18, 50-65.

Li, Yongjun. (2008). Research on fixed cost allocation based on data envelopment model. He Fei, University of science and technology of China.

Liu, Lingli. (2008). Analysis of the efficiency changing of the S \& T resources allocation and the influential elements in China. Science of Science and Management of $S \& T, 7,13-19$.

Miller, S., \& M. Upadhyay. (2002). Total Factor Productivity and the Convergence Hypothesis. Journal of Macroeconomics, 24, 267-286. http://dx.doi.org/10.1016/S0164-0704(02)00022-8

Niu, Shuhai, Jin, Fengjun, \& Liu, Yi. (2004). Regional differentiation of science \& technology resource allocation in China. Resources Science, 26, 61-68.

Wei, Shouhua, \& Wu, Guisheng. (2005). Research on the efficiency of regional science and technology resource allocation. Studies in Science of Science, 23, 468-473.

Wu, Huaqing, Liang, Liang, \& Li, Yongjun. (2009). A data envelopment analysis game model for resource allocation with input constraint. Systems Engineering, 27, 104-107.

Yang, Hongtao. (2007). Allocation efficiency of science and technology resources of towns of industry clusters in guangdong province. Forum on Science and Technology in China, 12, 102-105.

Yu, Yongze. (2009). Research on innovation efficiency and affecting factors of China High-Tech Industry - two-stage analysis based on value chain. Economic Science, 4, 62-74.

Zhou, Linquan. (2010). Performance evaluation index system Design about scientific and technological innovation policy. China Management Informationization, 1, 50-53. 